\title{
Google Forms Quizzes and Substitution, Augmentation, Modification, and Redefinition (SAMR) Model Integration
}

\author{
Scott Castro \\ Boise State University
}

\begin{abstract}
Web-based formative assessment technology has simplified how teachers capture and analyze student data. As an assessment and data gathering web-based application, Google Forms quizzes can be used to adapt content, individualize instructional goals, collect performance data, and connect students and teachers locally or from different parts of the world. Teachers can create and distribute Google Forms' formative assessment technology, resulting in synchronous student performance feedback that communicates critical information related to learning objectives for teachers and students. In addition, Google Forms quizzes can be exclusively aligned and integrated with the technology benchmarks defined in the Substitution, Augmentation, Modification, and Redefinition (SAMR) Model, resulting in the creation of dynamic and customizable formative assessments in ways never before conceptualized.
\end{abstract}

Keywords: Google Forms; formative assessment; SAMR Model; online collaboration; synchronous feedback

Google Forms is a free web-based data gathering tool part of the Google Suite applications by Google Cloud. Google Forms can be used to create surveys, polls, and formative assessment quizzes. Google Forms quizzes allow teachers to create, share, collaborate, individualize, and distribute formative assessments to students, providing synchronous feedback that generates measurable performance data which is critical for evaluating student progress. Nicol and Macfarlane (2005) suggested "good feedback practice is not only about providing accessible and usable information that help students improve their learning, but it is also about providing good information to teachers" ( $p$. 14). Synchronous formative feedback has become a direct line for student self-regulated learning (SLR) and instructional intervention, serving as an "important process as teachers strive to instill SRL characteristics among their students" (Clark, 2012, p. 8). Researchers agree formative assessment impacts the quality of teaching and learning, and it engages students in SRL and self-directed learning (SDL) environment which can be consummated using Google Forms quizzes (Stiggins, Arter, Chappuis, J., \& Chappuis, $S$, 2004). Google Forms quizzes have an assortment of optional design features that produce data for students and teachers. These optional design features, located in the quiz creation Settings tab, include: 
1. Missed questions, which show which questions were answered incorrectly;

2. Correct answers, which show the correct answer for each question;

3. Point values, which shows total points and points received for each question ("Choose a question for your form", 2018).

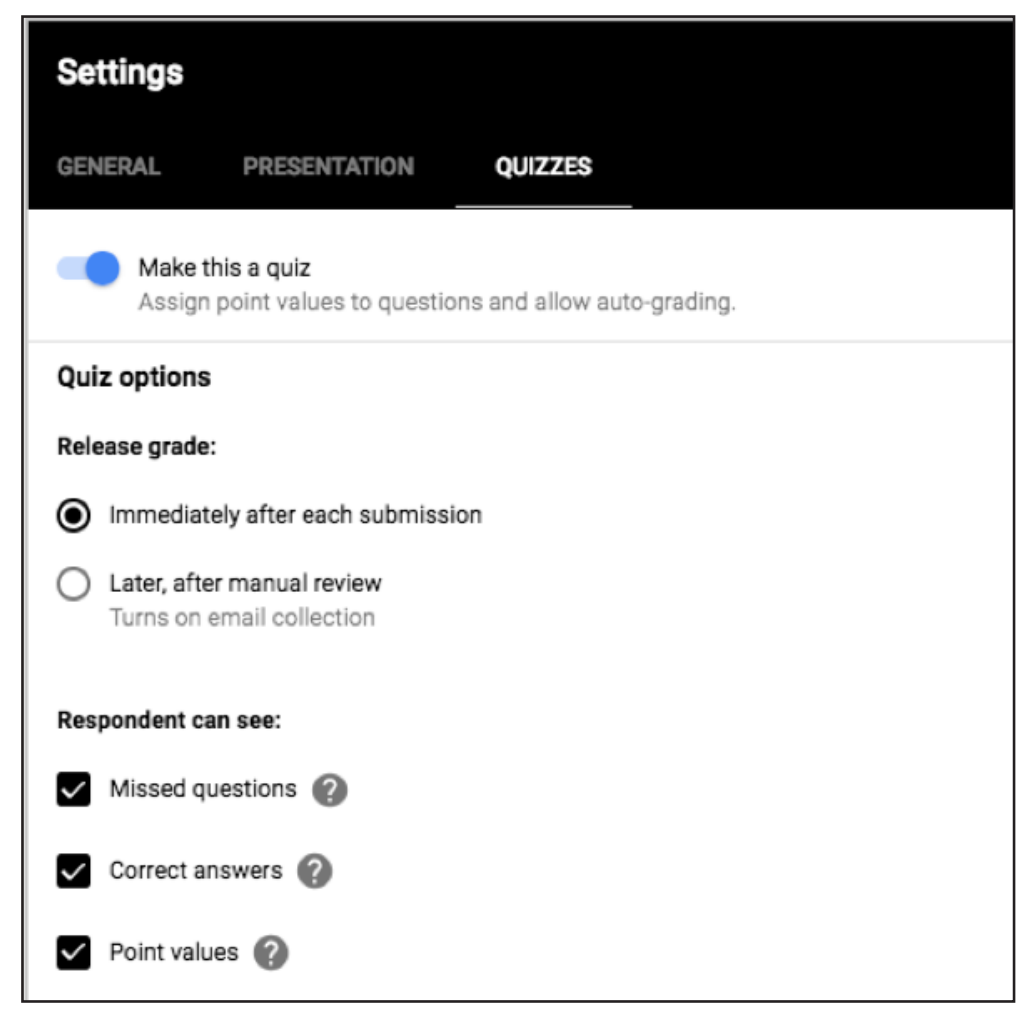

Figure 1. Google Form quiz settings. Reproduced from Google Forms. Retrieved from https://support.google.com/docs/answer/7032287?hl=en. Copyright 2018, Google.

Google Form quizzes include short response and multiple choice question types, but only multiple choice questions provide synchronous feedback data. Complete question design options in Google Forms quizzes include short response, multiple choice, checkbox, linear scale, and grid ("Getting started with Google Forms", 2016). Multiple choice and checkbox questions share design characteristics including a horizontal linear display, similar to traditional answer sheets. Additionally, multiple choice answers display in a circular format, analogous to traditional bubble sheet recording documents like scantrons. One variance is checkbox answer choices. Checkbox answer choices allow teachers to design questions that authorize students to select more than one answer choice. The more than one answer choice alternative follows logically with contemporary computer-based K-12 Common Core assessments. For example, the Smarter Balanced Assessment Consortium (SBAC) exam presently administered in fifteen states (Gewertz, 2017), defines the function of selecting more than one answer choice as "multiple choice, multiple correct responses" ("Smarter Balance Question Types”, 2016). This optional 
design function allows teachers to provide an equivalent testing framework to SBAC. Google Forms quizzes include several general features that provide security measures and data access by students. The general features in Google Forms quizzes include:

4. Collecting emails and sending receipts;

5. Restricted and required sign-in;

6. Limit to one response per user or allow multiple;

7. Respondent can edit after quiz submission;

8. Respondent sees a summary of charts and text responses ("Choose a question for your form" 2018).

This review will explore Google Forms quizzes as a formative assessment tool and provide comprehensive examples and integration strategies in correlation with SAMR Model technology benchmarks.

\section{Interpreting Formative Assessment}

There are several definitions of formative assessment. Black and Wiliam (1998a) described formative assessment as "encompassing all those activities undertaken by teachers, and/or by their students, which provide information to be used as feedback to modify the teaching and learning activities in which they are engaged" (p. 7). Black and Wiliam later re-examined this definition to include the notion that assessments become formative "when evidence is actually used to meet the needs of students" (1998b. p. 140). Expanding on Black and Wiliam's definition, Broadfoot Daugherty, Gardner, Gipps, Harlen, James, and Stobart (1999) argued that improving learning through assessment depends on the following five factors:

"(1) the provision of effective feedback to pupils; (2) the active involvement of pupils in their own learning; (3) adjusting teaching to take account of the results of assessment; (4) a recognition of the profound influence assessment has on the motivation and selfesteem of pupils, both of which are crucial influences on learning; and (5) the need for pupils to be able to assess themselves and understand how to improve." (p. 7).

Furthermore, Black, Harrison, Lee, Marshall, and Wiliam (2004) argued an assessment activity can assist learning if it produces information that teachers and their students can use as feedback in assessing themselves and one another. Most teachers agree that formative assessment is a continuous instructional process that follows closely to the provisions Broadfoot et al. presented, rationalizing that its purpose is to evaluate, improve, and support student learning. An example of this process could be observed when a student is assigned a critical response essay aligned with specific learning objectives. As an assessment tool, a teacher can use a rubric wherein feedback is recorded, offering 
personalized feedback with the intent of providing a means for the student to improve their writing. During this process, both student and teacher evaluate student performance and address potential needs to improve upon prior performance. Black et al. (2004) supported this affirmation by suggesting such an assessment becomes formative when the "evidence is actually used to adapt the teaching work to meet learning needs" (p. 10). In the preceding critical response writing example, a student can amend their work based on teacher feedback, and the teacher can use results to facilitate focused and guided instructional objectives. When interpreting student feedback, formative assessment provides an instructional framework for teachers, often distributing measures to adapt, individualize, and differentiate instructional goals to support students. It is critical to consider "an assessment activity can help learning if it provides information that teachers and their students can use as feedback in assessing themselves and one another and in modifying the teaching and learning activities in which they are engaged" (Black et al., 2004, p. 10). Despite varying interpretations and definitions of formative assessment, one can summarize it as a procedure "carried out during the instructional process for the purpose of improving teaching or learning" (Hammerness \& Rust, 2005. p. 275) that "is used to provide information on the likely performance of students... where feedback is given to students...telling them which items they got correct" (Wiliam \& Thompson, 2008, p. 60). Google Forms quizzes authorize teachers to deliver formative assessment tasks to their students, allowing the creation of dynamic and original content that can be integrated into all four technology benchmarks of the SAMR Model.

\section{The SAMR Model}

Developed in 2006 by Dr. Ruben Puentedura as part of his work with the Maine Learning Technology Initiatives, the SAMR Model "provides a framework for teachers designed to improve the integration of emerging technologies into their daily lessons" (Hilton, 2017, p. 68). Within this framework, the SAMR Model deploys a hierarchical structure, consisting of four distinct levels with specific technology integration benchmarks. These levels and benchmarks include:

- Substitution: technology acts as a tool substitute, with no functional change;

- Augmentation: technology acts as a direct tool substitute, with functional improvement;

- Modification: technology allows for significant task redesign;

Redefinition: technology allows for the creation of new tasks previously inconceivable (Puentedura, 2013).

The SAMR Model follows closely with recent revisions of Bloom's Taxonomy. Forehand (2011) described Bloom's Taxonomy as a "multi-tiered model of classifying thinking according to six cognitive levels of complexity" (p.42). These classifications from lower- 
level to higher-order thinking go as follows: Knowledge, Comprehension, Application, Analysis, Synthesis, and Evaluation. In 2001, former Benjamin Bloom student Lorin Anderson revised Bloom's Taxonomy and published a new list of categories from lower to higher-order thinking (Churches, 2008, p. 2). Anderson's changes included eliminating the noun form of each classification and replacing them with verbs. The revised lower to higher-level order thinking goes as follows: Remembering, Understanding, Applying, Analyzing, Evaluating, and Creating (Churches, 2008). Each revised level of Bloom's Taxonomy can be connected to SAMR benchmarks. For example, Substitution and Augmentation in the SAMR Model enhance learning, suggesting they serve to utilize technology to replace or improve upon traditional learning exercises with technology. Puentedura (2014) recommended that Substitution and Augmentation be associated with the "three lower levels of Bloom (Remember, Understand, and Apply)" (para. 3). The tasks of Modification and Redefinition transform learning, creating new opportunities that were previously unattainable through traditional measures absent of technology (Kirkland, 2014). Puentedura noted "Modification and Redefinition are associated with the upper levels of Bloom" including Analyze, Evaluate, and Create (Puentedura, 2014, para. 3). Although the connection to Bloom can be used "it is important to realize the association between SAMR and Bloom's Taxonomy is not a necessary or even habitual coupling...the simple structure described is well-suited to beginning practitioners' needs and even retains usefulness for more experienced faculty" (Puentedura, 2014, para. 5).

It is worth taking into consideration that using Bloom's Taxonomy as a framework with SAMR presents a familiarity to teachers, allowing for the likelihood of an uninterrupted transition when integrating technology into learning tasks. Teachers must also consider the rapid development of new technologies being considered for classroom integration. Because of this, SAMR benchmarks and how they are achieved appear to be in constant fluctuation due technology enhancements and improvements. These improvements and enhancements have a direct impact on decision making by beginning and advanced technology educators and play a critical role when implementing SAMR. With this taken into consideration, each SAMR Model benchmark related to Google Forms quizzes integration will be presented in further detail, beginning with Substitution.

Substitution. Hockly (2013) stated that Substitution is the simplest way to implement mobile learning, and when evaluating whether an activity is a part of the Substitution phase, Puentedura (2015) posed the question, "What will be gained by replacing older technology with the new technology?" (p.3). Hilton (2017) defined Substitution as the "use of technology for a task that could be accomplished without technology" making technology gains at this stage insignificant (p. 68). For example, during a traditional quiz, when students are presented with multiple choice or written response questions, they are required to use a writing tool, like a pencil or pen to record responses. The assessment delivery method is tangible, including a test and answer document. As a direct tool substitute, Google Forms quizzes can accomplish these objectives without functional modifications using mobile or laptop technology. For example, Google Forms quizzes may include both multiple choice and short response questions. Instead of using a traditional pen or pencil to record responses, students use a keyboard, mouse, and 
touch technology. Even though administering a Google Forms quiz with mobile or laptop technology differs from a traditional multiple choice and written response assessment, the outcome effectuates no functional change notwithstanding the present technology hardware. As teachers explore the design options in Google Forms quizzes, they will discover advancement beyond the Substitution phase of the SAMR Model. When transitioning from Substitution to Augmentation, teachers must investigate if they have added an improvement to the task process that could not be accomplished with older technology and explore if this feature contributes to the design (Puentedura, 2013).

Augmentation. Learning activities positioned within the Substitution and Augmentation classifications are said to enhance learning. In the Augmentation phase, "Technology acts as a direct tool substitute with functional improvement" (Puentedura, 2013). To establish whether Google Forms quizzes provide a functional improvement, one must consider the default accessibility functions on laptops and mobile devices. Traxler (2010) stated, "Mobile devices, especially connected devices, enable students to consume - that is, to access and store-all sorts of knowledge almost instantly and almost wherever they are, with little or no effort compared with earlier technologies" (p. 154). For example, when using an Apple iOS device to take a Google Forms quiz, students can select an unknown word and use the define technology. The result of this process is a dictionary pop-up window that displays the definition of the word and a thesaurus. These options allow students to acquire vocabulary parallel to their independent skill level. Define technology is a functional improvement over traditional dictionary and thesaurus counterparts because the student has immediate access to word definitions and synonyms. In a learning environment without this technology, the process of looking up words in physical texts is prolonged and can take away from instructional time. Along with define options, iOS devices also include speak technology. Speak technology allows students to have a phonetic pronunciation of a word spoken to them, including customizable accents. Speak technology is a functional improvement because content adjusts to learning styles, providing a phonetic media alternative not available in traditional dictionaries. It is worth detailing that speak and define technologies are not design features of Google Forms quizzes; instead, they are embedded accessibility tools on laptops, desktops, and mobile devices.

Further functional improvements in the Augmentation phase include sharing and accessing Google Form quizzes remotely. Accessing quizzes remotely empowers teachers to use a flipped learning pedagogical approach, so students can access and complete content prior to attending class. Additionally, Google Forms quizzes can integrate video and photos into multiple choice and short response question sequencing. This feature is a functional improvement because it merges media into quizzes, following logically with media-driven questioning presented during computer-based state assessments like SBAC. Video integration in Google Forms quizzes is limited to YouTube content and may present challenges to teachers at school because of potential YouTube networking blocking. Despite these limitations, most YouTube content contains automated closedcaptioning technology which can be used to individualize Google Forms quizzes for students with hearing impairments or other learning disabilities. 
Photo integration with Google Forms quizzes allows more flexibility than videos. Teachers can upload photo media from a screenshot, hard drive, URL, Google Photo Albums, browser search, and Google Drive. Photo integration can also be used for multiple choice answers, making it adaptive for visual learners. However, photo integration lacks meta descriptions of photos, which is not equitable for students with visual impairments, something teachers should take into consideration. Additional functional improvements in Google Forms quizzes include creating distinct numerical point values for questions, randomizing answer choices, restricting quizzes to specific users, allowing users to or not to edit responses, and permitting users to take a quiz multiple times or only once.

Modification. Learning activities positioned within the Modification and Redefinition classifications transform learning. When in the Modification phase, "Technology allows for significant task redesign" (Puentedura, 2013). First, upon completion of a Google Forms quiz, students receive immediate performance feedback. Winne and Butler (1994) describe feedback as "information with which a learner can confirm, add to, and overwrite, tune, or restructure information in memory" (p. 5740). Unlike traditional pen and paper formative multiple-choice assessments, feedback for Google Forms multiple choice questioning allows teachers to enable an immediate auto-grading feature that shows incorrect and correct answers and question point values. It is critical for quiz feedback to be visibly aligned with questions, allowing students to regulate their learning. Clark and Mayer (2011) supported this design technique in their cognitive multimedia research, concluding "When feedback is provided on a page separate from the quiz question to which it is referring, it is more difficult for the learner to relate the feedback to the quiz response" (pg. 92). The inclusion of answers with questions should be taken into consideration by teachers designing Google Form quizzes so students can self-regulate learning. Question point values and written answer feedback must be set by the teacher and can be customized for each question and displayed when a quiz is completed. Additionally, teachers can enable permissions for students to observe whole class scoring data when they finish the quiz, so that they can measure performance outcomes relative to peers. It is worth noting students do not have access to individual student scores with this feature, only question-to-question class data provided in graph format. Enabling these functions allows quality feedback and communication among teacher and student. Nicol and Macfarlane (2005) asserted "quality feedback is information that helps students troubleshoot their own performance and self-correct: that is, it helps students take action to reduce the discrepancy between their intentions and the resulting effects" (p. 10).

Another way that Google Forms quizzes modify task redesign is through creating conditional logic-branching questions. Conditional logic-branching questions allow teachers to create a quiz with unique sections of questions. For example, when taking a quiz with logic-branching questions, students can complete the assessment more rapidly based on correct answer selections. In contrast, if students answer questions incorrectly during conditional logic-branching questioning, the quiz will could continue until students show mastery of content. Conditional logic-branching questions authorize teachers to gather valuable feedback "prioritizing areas of improvement" (Nicol \& Macfarlane, 2005), 
by adapting in real-time based on student understanding. The inclusion of conditional logic-branching questions and synchronous feedback communicates a significant task redesign with technology, allowing teachers to deliver innovative technology integration for students.

Redefinition. In the Redefinition phase, "Technology allows for the creation of new tasks, previously inconceivable" (Puentedura, 2013). Redefinition is the highest phase in the SAMR Model, and teachers must first explore the Share features in Google Forms quizzes to connect with teachers and students. For example, teachers and students from different schools can work collaboratively to create and produce personalized Google Forms quizzes by utilizing the quiz sharing option. One example of how this activity can work is having teachers from different schools in the same school district collaborate, create, and produce a series of shared Google Forms quizzes related to shared curriculum. When a Google Forms quiz is finalized, the teachers could share it on a learning management system like Google Classroom so students can assess their understanding of the topic. Upon completion of the quiz, students from both schools could engage in a discussion board related to the quiz topic. They can engage in a collaborative analysis discussion on the performance data, allowing for the construction of new knowledge. In this example, Google Forms quizzes serve as not only a formative assessment tool but also one that connects students to shared learning goals through communication and collaboration, creating a transformative technological task.

Using the 'share' function in Google Forms quizzes is not limited to teachers in the same school or district. Teachers can also connect with a broader range of technology educators all over the world using Google Education Groups (GEGs). GEGs are "communities of educators who learn, share, and inspire each other to meet the needs of their students through technology solutions, both in the classroom and beyond" ("Google Educator Groups", 2018). GEGs are created with the social media platform, Google Plus, and are for teachers that aspire to innovate students with technology. Once teachers create a GEG or join one in progress, they can establish shared learning goals with group educators and proceed to share, collaborate, and create Google Forms quizzes, resulting in the creation of new opportunities for students and teachers to connect and collaborate on a global scale. In GEGs, Google Forms quizzes can be administered on a Google Plus message board, so students and teachers can gather, analyze, and interpret data from all participating group members. This example is transformative because it creates a global task using technology that was previously implausible, redefining how teachers can connect themselves and students to one another around the world.

\section{Google Forms Quizzes Limitations}

With most technology, it is practical when administered by individuals that have proper training. To effectively use Google Form quizzes, it is suggested teachers become qualified with implementation strategies by becoming a Google Certified Educator or undergoing similar professional development. Completing certification or professional 
development requires time and money, something teachers may not have the opportunity to pursue, presenting a potential barrier. Also, Google Forms quizzes require an internet connection. The 2013 US Census reported the population at 316,200,000 million with $98 \%$ having access to the internet ("Computer Use and the Internet", 2014). This data concludes that $2 \%$ of the United States population, some of which are students, are without internet access, creating potential concerns for student connectivity to Google Forms quizzes. Moreover, in a school setting, Google Forms quizzes may encounter network security that prohibits administering assessments that contain embedded media content, creating a potential obstruction for teachers that want to embed media content for students with physical or learning disabilities. Lastly, GEG meetings could become complicated because of the varying time zones of participates, making it problematic for teachers and students to communicate in real time.

\section{Conclusion}

As a web-based formative assessment tool, and with careful consideration, Google Forms quizzes can achieve all four SAMR Model technology benchmarks. When designing Google Forms quizzes using SAMR model benchmarks, teachers can embed media content, design logic-branching questioning, individualize and adapt content, and provide students with synchronous feedback and data to support learning through selfregulation. Additionally, teachers can communicate and share Google Form quizzes in a global domain, reaching students and teachers in venues never before conceptualized.

Despite the enhanced and transformative functions in Google Forms quizzes, not all teachers achieve each SAMR benchmark. Having this expectation is unrealistic. Instead, SAMR can be interpreted as a guide or reflective framework for beginning and advanced teachers that aspire to integrate more technology into lessons. Moreover, it is critical to take into consideration not all teachers maintain comparable technology skills. For teachers using SAMR as a model for integration, they should work in the levels they have determined familiar and comfortable, so they never force SAMR integration. Despite varying pedagogical approaches to SAMR integration in the classroom, Google Forms quizzes permit beginning and experienced technology educators with opportunities to carry out SAMR Model benchmarks, functioning as a valuable formative assessment tool for teachers and students. 


\section{References}

Anderson, L. W., \& Krathwohl, D. R. (2001). A taxonomy for learning, teaching, and assessing: a revision of Bloom's taxonomy of educational objectives. New York: Longman.

Black, P., Harrison, C., Lee, C., Marshall, B., \& Wiliam, D. (2004). Working inside the black box: Assessment for learning in the classroom. Phi Delta Kappan, 86(1), 8-21.

Black, P. J., \& Wiliam, D. (1998a). Assessment and classroom learning. Assessment in Education: Principles, Policy, and Practice, 5(1), 7-73.

Broadfoot, P. M., Daugherty, R., Gardner, J., Gipps, C. V., Harlen, W., James, M., et al. (1999). Assessment for learning: beyond the black box. Cambridge, UK: University of Cambridge School of Education.

Butler, D.L., \& Winne, P.H. (1995). Feedback and self-regulated learning: a theoretical synthesis. Review of Educational Research, 65(3), 245-281.

Churches, A. (2008). Bloom's taxonomy blooms digitally. Tech \& Learning, 1, 1-6.

Clark, I. (2012). Formative assessment: assessment is for self-regulated learning. Educational Psychology Review, 24 (2), 205-249.

Clark, R. C., \& Mayer, R. E. (2011). E-Learning and the science of instruction: proven guidelines for consumers and designers of multimedia learning (3rd ed.). San Francisco, CA: John Wiley \& Sons.

Docs Editors Help: Choose a question for your form (2018). Retrieved April 02, 2018, from https://support.google.com/docs/answer/7322334?hl=en

Forehand, M. (2010). Bloom's taxonomy. Emerging Perspectives on Learning, Teaching, and Technology, 41, 47.

Gewertz, C. (2017). Which states are using PARCC or Smarter Balanced: an interactive breakdown of states' 2016-17 testing plans. Education Week, 36 (21). Retrieved from https://www.edweek.org/ew/section/multimedia/states-using-parcc-orsmarter-balanced.html

Google Educator Groups. (n.d.). Retrieved April 22, 2018, from https://www.google. com/landing/geg/

Google Learning Center: Get started with forms (2016). Retrieved from https://gsuite. google.com/learning-center/products/forms/get-started/ 
Hilton, J. T. (2016). A case study of the application of SAMR and TPACK for reflection on technology integration into two social studies classrooms. The Social Studies, 107(2), 68-73, doi: 10.1080/00377996.2015.1124376

Hockly, N. (2013). Technology for the language teacher: mobile learning. ELT Journal, $67(1), 80-84$.

Kirkland, A. (2014). Models for technology integration in the learning commons. School Libraries in Canada 32(1), 14-18.

Nicol, D. J., \& Macfarlane-Dick, D. (2006). Formative assessment and self-regulated learning: a model and seven principles of good feedback practice. Studies in Higher Education, 31(2), 199-218.

Puentedura, R. (2013). Moving from enhancement to transformation. Retrieved from http://www.hippasus.com/rrpweblog/ archives/2013/05/29SAMREnhancementtToTransformation.pdf

Puentedura, R. (2014). SAMR and Bloom's Taxonomy: assembling the puzzle. Retrieved from https://www.commonsense.org/education/blog/samr-andblooms-taxonomy-assemblingthe-puzzle

Smarter Balanced Question Types. (2016). Retrieved from http://www.cde.ca.gov/ta/tg/ sa/question-types.asp

Stiggins, R. J., Arter, J. A., Chappuis, J., \& Chappuis, S. (2004). Classroom assessment for student learning: doing it right--using it well. Portland, Oregon: Assessment Training Institute.

U.S. Census Bureau (2014). Computer and internet use in the United States. 2013 American Community Reports. Retrieved from https://www.census.gov/history/ pdf/2013computeruse.pdf

Wiliam, D., \& Thompson, M. (2017). Integrating assessment with learning: what will it take to make it work? (pp. 53-82). Routledge. 